\title{
Elevated Activity of Cathepsin L-like Protease in the Jellied Meat of Japanese Flounder
}

\author{
Haruhiko Toyohara, ${ }^{{ }_{1}}$ Masato Kinoshita, ${ }^{* 1}$ Masashi Ando, ${ }^{*},{ }^{*}{ }_{2}$ \\ Michiaki Yamashita, ${ }^{* 3}$ Shiro Konagaya, ${ }^{* 3}$ \\ and Morihiko Sakaguchi*1 \\ (Received May 20, 1993)
}

\begin{abstract}
The cause of the jelification of Japanese flounder meat was investigated. Infection by parasites was not histologically detected, while the arrangement of myofibrils was notably disturbed. Large amounts of trichloroacetic acid soluble materials and a breakdown of myosin heavy chain suggested the occurrence of proteolytic degradation in the jellied meat.

Crude extract of the jellied meat showed proteolytic activity on myosin heavy chain, which was hardly detected in the normal meat. The extract hydrolyzed Z-Phe-Arg-MCA most preferentially among the synthetic peptide substrates tested. Activities on myosin heavy chain and Z-Phe-Arg-MCA were inhibited by leupeptin, antipain, and E-64, but not by soybean trypsin inhibitor or pAPMSF (a specific inhibitor for trypsin-like proteases), suggesting that the activities were ascribed to a cysteine protease(s). Both myosin heavy chain and Z-Phe-Arg-MCA hydrolyzing activities were co-eluted from TSK G3000SWXL column at an eluting position whose molecular weight corresponded to 34,000 . Together with these results, the protease activity elevated and possibly involved in the jelification of Japanese flounder meat was taken to be due to an endogenous cathepsin L-like protease.
\end{abstract}

Jellied meat is a fish muscle whose toughness is considerably lowered, and sometimes muscle is even reduced to liquified paste. According to the classification of jellied meats by Konagaya, ${ }^{\text {") }}$ those of flat fish so far reported are classified into the following two types on the basis of infection by parasites: (1) Jellied meat of halibut Hippoglossus stenolepis, ${ }^{2,3)}$ lemon sole Parophrys vetulus, ${ }^{4)}$ Dover sole Microsomus pacificus, ${ }^{5)}$ petrale sole Eopsetta jordani, ${ }^{, 2}$ starry flounder Platichthys stellatus, ${ }^{5)}$ yellowfin sole Limanda aspera, ${ }^{6)}$ and arrowtooth fluounder Therethes stomias ${ }^{7}$ accompanied by infection by myxosporidian parasites; and (2) that of American plaice Hippoglossoides platessoides $^{8}$ ) and Mexican flounder Paralichthys squamalentus ${ }^{8)}$ not accompanied by infection.
Jellied meat of Japanese flounder Paralichthys olivaceus, known as nori (a Japanese word meaning "paste") or fukuro (a Japanese word meaning "bag"), has been observed in Japan. Since these jellied meats are no longer suitable as materials either for raw fish dishes or for cooked dishes, most of them are supposedly abandoned. The present study was undertaken to clarify the cause of jelification of Japanese flounder meat.

\section{Materials and Methods}

\section{Materials}

Wild Japanese flounder demonstrating gelification were brought to our laboratory by commercial suppliers. These fish $(55-65 \mathrm{~cm}$ in body

*1 Laboratory of Fishery Chemistry, Department of Fisheries, Faculty of Agriculture, Kyoto University, Kitashirakawa, Sakyo, Kyoto 606-01, Japan（豊原治应，木下政人，安藤正史，坂口守浐：京 都大学農学部).

*2 Present address: Laboratory of Marine Food Technology, Department of Fisheries, Faculty of Agriculture, Kinki University, Nara 631, Japan (近畿大学装学部).

*3 National Research Institute of Fisheries Science, Ministry of Agriculture, Forestry and Fisheries of Japan, Fukuura, Kanazawa, Yokohama 236, Japan（山下偷明，小長谷史郎：中头水磁究所). Abbereviations: AMC, 7-amino-4-methylcoumarin; E-64, L-trans-epoxysuccinyl-leucylamido-(4guanidinobutane); MCA, 4-methylcoumaryl-7-amide; pAPMSF, ( $p$-amidophenyl)methanesulfonyl fluoride; SDS-PAGE, sodium dodecyl sulfate-polyacrylamide gel electrophoresis; STI, soybean trypsin inhibitor; $Z$, benzyloxycarbonyl. 
length and $2.2-2.5 \mathrm{~kg}$ in body weight) were presumably stored for a couple of days under chilled conditions after being captured. The degree of gelification varied from fish to fish and even within the muscle portion of the same fish body.

\section{Histological Observation}

Detection of parasites was carried out by methylene blue staining of smeared muscle on a slide glass or hematoxylin and eosin staining of thin sections of $6 \mu \mathrm{m}$ of the paraffin-embedded sample.

\section{Detection of Proteolysis in the Jellied Meat}

Muscle excised from the jellied meat and the normal meat of the same fish body was homogenized with 10 parts of water by using a Polytron homogenizer (Kinematica, Switzerland) at maximum speed for $1 \mathrm{~min}$. The obtained homogenate was mixed with an equal volume of $5 \%$ trichloroacetic acid and filtered through Toyo No. 3 filter paper. The amount of peptides and amino acids in the filtrate was evaluated by the method of Lowry et al. ${ }^{10}$

For the electrophoretic analysis, muscle was homogenized with 5 parts of $20 \mathrm{~mm}$ sodium phosphate buffer, pH 6.8, using a Polytron homogenizer at maximum speed for $1 \mathrm{~min}$. The obtained homogenate was centrifuged at $10,000 \times \mathrm{g}$ for $15 \mathrm{~min}$. Protein composition of the precipitate (myofibrillar fraction) and the supernatant (sarcoplasmic fraction) was examined by SDS-PAGE in a $10 \%$ gel. ${ }^{11}$

\section{Preparation of the Crude Protease Solution}

Muscle was homogenized with 5 parts of $50 \mathrm{~mm}$ sodium phosphate buffer, pH 6.3, containing $5 \mathrm{~mm}$ 2-mercaptoethanol and $1 \mathrm{~mm}$ EDTA by using a Polytron homogenizer at maximum speed for $1 \mathrm{~min}$. The obtained homogenate was centrifuged at $10,000 \times \mathrm{g}$ for $30 \mathrm{~min}$ and the supernatant was used as the crude protease solution.

Partial purification of the protease was carried out on a column $(0.75 \times 30 \mathrm{~cm})$ pf TSK G3000SWXL (Toso) with a Shimadzu LC 7A HPLC system.

\section{Assay of the Protease Activity}

Myosin heavy chain hydrolyzing activity was determined as follows. The reaction mixture consisted of $50 \mathrm{~mm}$ sodium phosphate buffer, $\mathrm{pH}$ $6.3,20 \mathrm{mg}$ threadfin-bream myofibril prepared as described previously, ${ }^{12}$ ) and an aliquot of the protease solution in a total volume of $1 \mathrm{~m} l$. The reaction was carried out at $37^{\circ} \mathrm{C}$ for $1 \mathrm{~h}$ and stopped by the addition of $0.1 \mathrm{ml}$ of $1 \mathrm{M}$ Tris$\mathrm{HCl}, \mathrm{pH} 6.8$, containing $10 \% \mathrm{SDS}$ and $50 \mathrm{~mm}$ 2-mercaptoethanol and subsequent heating at $100^{\circ} \mathrm{C}$ for $3 \mathrm{~min}$. Thirty micrograms of protein were subjected to analysis by SDS-PAGE in a $10 \%$ gel. ${ }^{11}$ Staining was carried out by Coomassie Brilliant Blue R-250.

Synthetic substrate hydrolyzing activity was determined as follows. The reaction mixture consisted of $50 \mathrm{~mm}$ sodium phosphate buffer, $\mathrm{pH}$ $6.3,0.2 \mathrm{~mm}$ substrate, and an aliquot of the protease solution in a total volume of $1.5 \mathrm{ml}$. The reaction was performed in a crystal cell kept at $37^{\circ} \mathrm{C}$, and the increase of the fluorogenic intensity was directly monitored on a Hitachi 204 fluorescence spectrophotometer (excitation at $380 \mathrm{~nm}$; emission at $460 \mathrm{~nm}$ ).

\section{Results and Discussion}

\section{Comparison of the Normal and Jellied Meats}

No parasite infection was histologically detected for the jellied meats from eight individual fish, either by methylene blue staining of the smeared muscle or by hematoxylin and eosin staining of the cross sections of the muscle fibers. Figure 1 shows the hematoxylin and eosin staining of cross sections prepared from the normal and jellied meats excised from the same fish. Disturbance in the arrangement of myofibrils was observed in case of the jellied meat, which might have led to muscle softening.

A larger amount of trichloroacetic acid soluble materials most probably composed of peptides and amino acids was demonstrated in the jellied meat (578 $\mu \mathrm{g}$ Tyr equivalent/g muscle) than in the normal meat (124 $\mu \mathrm{g}$ Tyr equivalent/g muscle). In addition, a loss in intensity of the myosin heavy chain band and the formation of possible breakdown products were demonstrated in the jellied meat, while myosin heavy chain seemed intact in the normal meat (Fig. 2). These results suggest that some proteolytic degradation occurred in the jellied meat. Changes in the intensity of several bands were also detected for the sarcoplasmic proteins in the jellied meat. However, the relationship between the changes in the sarcoplasmic proteins in the SDS-PAGE pattern and the jellification of the meat remains unknown.

\section{Proteolytic Activity in the Jellied Meat}

As shown in Fig. 3, the crude protease solution 

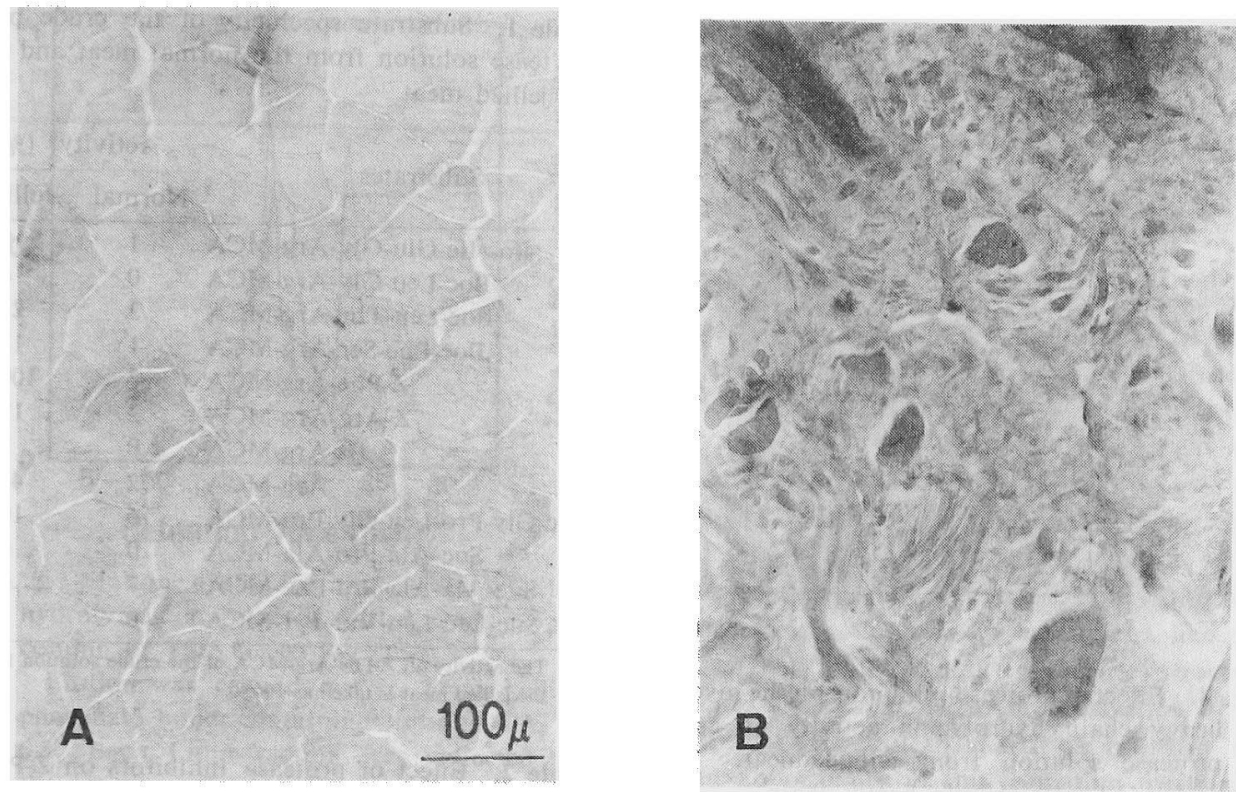

Fig. 1. Cross section of normal meat (A) and jellied meat (B) of Japanese flounder stained by hematoxylin and eosin. The bar indicates $50 \mu \mathrm{m}$.

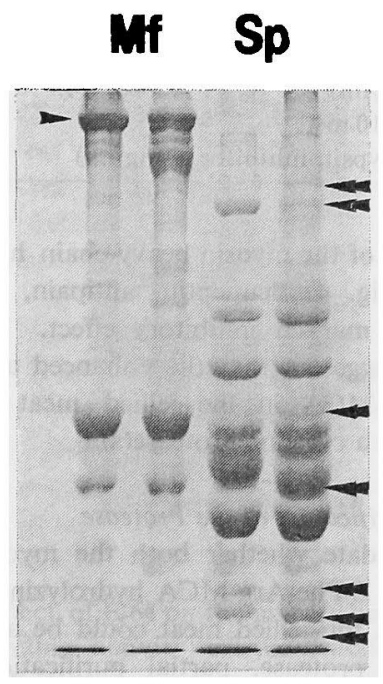

A B A B

Fig. 2. Protein composition of myofibrillar (Mf) and the sarcoplasmic $(\mathrm{Sp})$ fractions prepared from normal meat (A) and jellied meat (B).

The single-headed arrow indicates myosin heavy chain. The double-headed arrows indicate sarcoplasmic proteins whose intensities differ between the normal meat and the jellied meat.

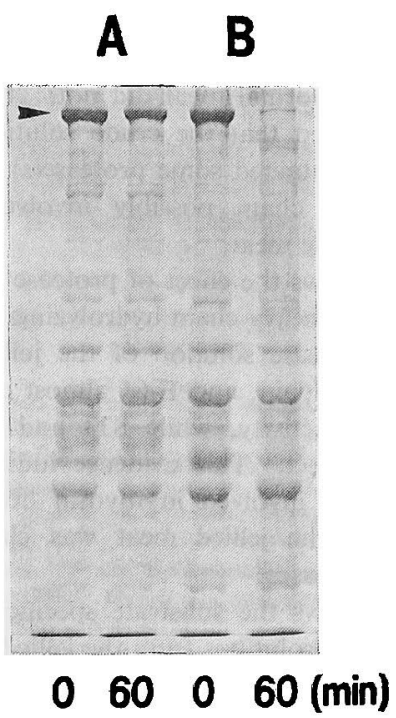

Fig. 3. Comparison of the threadfin-bream myosin heavy chain hydrolyzing activity of crude protease solutions from normal meat (A) and jellied meat (B). The arrow indicates myosin heavy chain. " 0 "; without incubation, "60"; incubated for $60 \mathrm{~min}$. 


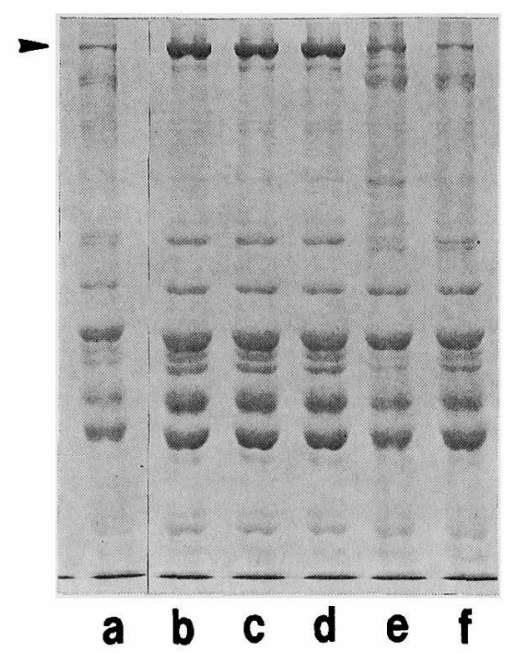

Fig. 4. Effect of protease inhibitors on the myosin heavy chain hydrolyzing activity of crude protease solution from jellied meat. The arrow indicates myosin heavy chain.

a, Without inhibitor; b, leupeptin $(10 \mu \mathrm{g} /$ $\mathrm{ml}) ; \mathrm{c}$, antipain $(10 \mu \mathrm{g} / \mathrm{ml}) ; \mathrm{d}$, E-64 $(10 \mu \mathrm{g} /$ $\mathrm{ml})$; e, pAPMSF $(10 \mathrm{~mm}) ; \mathrm{f}$, soybean trypsin inhibitor $(1 \mathrm{mg} / \mathrm{ml})$.

prepared from the jellied meat showed strong myosin heavy chain hydrolyzing activity, while that from the normal meat did not. This result clearly suggested that the crude solution of the jellied meat contained some protease(s) active on myosin heavy chain possibly involved in the jelification of the meat.

Figure 4 shows the effect of protease inhibitors on the myosin heavy chain hydrolyzing activity of the crude protease solution of the jellied meat. Leupeptin, antipain, and E-64 almost completely inhibited the activity, while STI and pAPMSF showed no effect. This evidence indicated that the protease(s) involved in myosin heavy chain hydrolysis in the jellied meat was classified as a cysteine proteases.

Table 1 shows the substrate specificity of the crude protease solutions from the jellied meat and the normal meat. Crude protease solution of the jellied meat showed markedly higher activities in substrates with Arg in the $\mathbf{P}_{1}$ position particularly on Z-Phe-Arg-MCA (a substrate for cathepsin L), while Arg-MCA (a substrate for cathepsin $\mathrm{H}$ ) hydrolyzing activity was lower in the jellied meat.

Table 2 shows the effect of protease inhibitors on the Z-Phe-Arg-MCA hydrolyzing activity of the crude protease solution of the jellied meat. As
Table 1. Substrate specificity of the crude protease solution from the normal meat and the jellied meat

\begin{tabular}{rcc}
\hline \hline & \multicolumn{2}{c}{ Activity* $(\%)$} \\
\cline { 2 - 3 } Substrates & Normal & Jellied \\
\hline Boc-Ile-Glu-Gly-Arg-MCA & 1 & 8 \\
Boc-Leu-Gly-Arg-MCA & 0 & 4 \\
Boc-Leu-Thr-Arg-MCA & 3 & 21 \\
Boc-Phe-Ser-Arg-MCA & 1 & 13 \\
Z-Phe-Arg-MCA & 3 & 100 \\
Z-Arg-Arg-MCA & 2 & 12 \\
Bz-Arg-MCA & 0 & 2 \\
Arg-MCA & 72 & 48 \\
Suc-Gly-Pro-Leu-Gly-Pro-MCA & 16 & 10 \\
Suc-Ala-Pro-Ala-MCA & 0 & 0 \\
Suc-Ala-Ala-Pro-Phe-MCA & 7 & 0 \\
Suc-Leu-Leu-Val-Tyr-MCA & 0 & 3 \\
\hline * The activity on Z-Phe-Arg-MCA of the crude solution from \\
the jellied meat is taken as 100\%.
\end{tabular}

Table 2. Effect of protease inhibitors on Z-PheArg-MCA hydrolyzing activity of the crude protease solution from the jellied meat

\begin{tabular}{lc}
\hline \multicolumn{1}{c}{ Inhibitors (concn.) } & $\begin{array}{c}\text { Remaining } \\
\text { activity }(\%)\end{array}$ \\
\hline None & 100 \\
Leupeptin $(10 \mu \mathrm{g} / \mathrm{m} l)$ & 0 \\
Antipain $(10 \mu \mathrm{g} / \mathrm{m} l)$ & 0 \\
E-64 $(10 \mu \mathrm{g} / \mathrm{m} l)$ & 0 \\
$p$ APMSF $(10 \mathrm{mM})$ & 93 \\
Soybean trypsin inhibitor $(1 \mathrm{mg} / \mathrm{m} l)$ & 109 \\
\hline
\end{tabular}

in the case of the myosin heavy chain hydrolyzing activity (Fig. 4), leupeptin, antipain, and E-64 showed a marked inhibitory effect. The result strongly suggested that the enhanced activity on Z-Phe-Arg-MCA in the jellied meat could be ascribed to a cysteine protease(s).

\section{Partial Purification of the Protease}

To elucidate whether both the myosin heavy chain and Z-Phe-Arg-MCA hydrolyzing activities elevated in the jellied meat could be ascribed to the same protease, partial purification of the protease was attempted. Figure 5 shows the elution profile of the Z-Phe-Arg-MCA hydrolyzing activity of the jellied meat from a column of TSK G3000SWXL. The peak of the activity was detected in the fraction eluted from 19-20 min. The molecular weight of the protease estimated from the elution position was around 34,000, which was slightly larger than that of salmon muscle cathepsin L. ${ }^{13)}$ The myosin heavy chain 


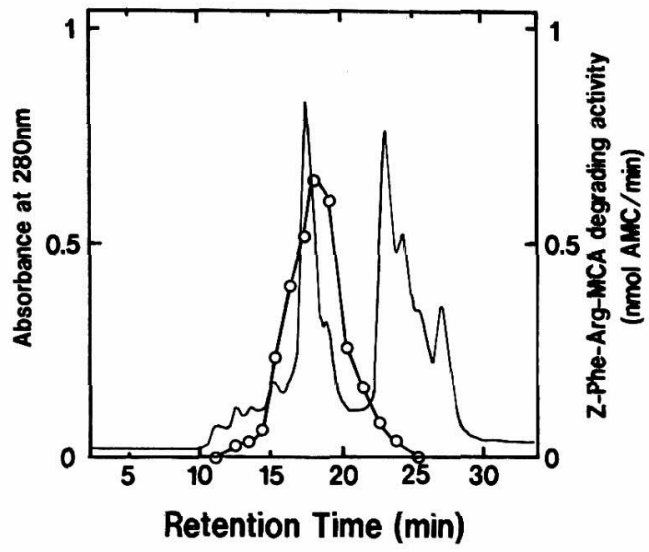

Fig. 5. Elution profile of the Z-Phe-Arg-MCA hydrolyzing activity of jellied meat from a column of TSK G3000 SWXL.

Elution was carried out by $20 \mathrm{~mm}$ sodium phosphate buffer containing $1 \mathrm{~mm}$ EDTA, pH 6.8. Each 1 min-fraction was collected and the activity was measured as described in the text. $\mathrm{O}-\mathrm{O}, \mathrm{Z}$-Phe-Arg-MCA hydrolyzing activity; - , absorbance at $280 \mathrm{~nm}$.

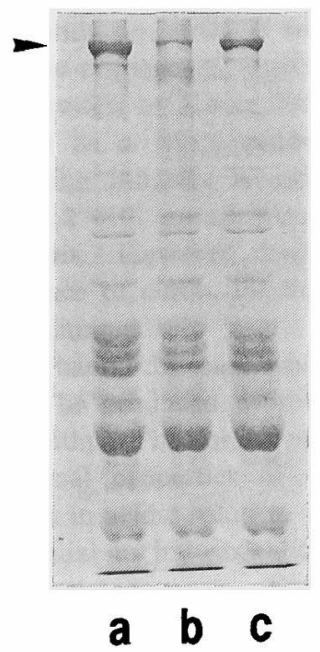

Fig. 6. Effect of E-64 on the myosin heavy chain hydrolyzing activity of the fraction eluted from $19-20 \mathrm{~min}$.

Lane "a" shows the sample without incubation. Lanes " $b$ " and "c" show the samples incubated without E-64 and with E-64 $(10 \mu \mathrm{g})$ $\mathrm{m} l$ ), respectively. The arrow indicates myosin heavy chain.

hydrolyzing activity was co-eluted with the $\mathrm{Z}$ Phe-Arg-MCA hydrolyzing activity and was not detected in other fractions. Figure 6 shows the myosin heavy chain hydrolyzing activity of the fraction eluted from $19-20 \mathrm{~min}$ in the absence or presence of E-64. This result demonstrates that the E-64 sensitive myosin heavy chain hydrolyzing activity which was detected in the crude protease solution shown in Fig. 4 could be ascribed to this protease.

Based on the results reported herein, the elevated protease activity possibly involved in the gelification of Japanese flounder meat was assumed to be due to an endogenous cathepsin L-like protease. Yamashita and Konagaya ${ }^{14)}$ reported that cathepsin $\mathrm{L}$ activity in chum salmon muscle was markedly elevated in the spawning season, which often led to muscle softening. In the case of the jellied meat of Japanese flounder, the relationship between maturation and the cathepsin L-like protease activity still remains unknown. However, it seems likely than the marked elevation of the cathepsin L-like protease activity is probably due to an abnormality in the regulating mechanism of the protease activity under some pathological condition. In addition, jellied meat not accompanied by infection by parasites ${ }^{8, \theta)}$ could be ascribed to the elevated activity of this type of protease.

\section{Acknowledgments}

This work was supported in part by grants for Scientific Research from the Ministry of Education and Culture, Japan and from the Japan Society of Bioscience, Biotechnology, and Agrochemistry.

\section{References}

1) S. Konagaya: A review of the abnormal conditions of fish meat: Jellied meat and yake-niku, spontaneously done meat. Nippon Shokuhin Kogyo Gakkaishi, 29, 379-388 (1982).

2) W.F. Thompson: A note on a sporozoan parasite of the halibut. Rept. Comm. Fish. British Columbia for 1915, 127129 (1916).

3) H.S. Davis: A new myxosporidian parasite, the cause of "wormy halibut. Rept. U. S. Comm. Fish. for 1923 Appendix VIII. 1 (1923).

4) C. R. Forester: The relation of stock density to "milkiness" of lemon sole. Fish. Res. Bd. Canada, Pac. Prog. Rept., 105, 11 (1956).

5) M. Patashnik and H. S. Groninger, Jr: Observation on the milky condition in some Pacific coast fishes. J. Fish. Res. Bd. Canada, 21, 335-346 (1964).

6) S. Konagaya: Jellification and protease activity of yellowfin sole muscle in association with a Myxosporidian parasite. Nippon Suisan Gakkaishi, 46, 1019-1026 (1980).

7) D. H. Greene and J. K. Babbitt: Control of muscle softening and protease-parasite interactions in arrowtooth flounder Atheresthes stomias. J. Food Sci., 55, 579-580 (1990).

8) W. Templeman and G. L. Andrews: Jellied condition in the 
American plaice Hippoglpssoides platessoides (Fabricius). J. Fish. Res. Bd. Canada, 13, 147-182 (1956).

9) T. D. Love: Report of "jellied" flounder from gulf of Mexico. Comm. Fish. Rev., 23, 9-10 (1961).

10) O. H. Lowry, N. L. Rosebrough, A. L. Farr, and R.J. Randall: Protein measurement with the Folin phenol reagent, J. Biol. Chem., 193, 265-275 (1951).

11) U. K. Laemmli: Cleavage of structural proteins during the assembly of the head of bacteriophage $T_{4}$. Nature, 227, 680-685 (1970).

12) H. Toyohara, M. Kinoshita, and Y. Shimizu: Proteolytic degradation of threadfin-bream meat gel. J. Food Sci., 55, 259-260 (1990).

13) M. Yamashita and S. Konagaya: Purification and characterization of cathepsin $\mathbf{L}$ from the white muscle of chum salmon, Onchorhynchus keta. Comp. Biochem. Physiol., 96B, 247-252 (1990).

14) M. Yamashita and S. Konagaya: Participation of cathepsin $L$ into extensive softening of the muscle of chum salmon caught during spawning migration. Nippon Suisan Gakkaishi, 56, 1271-1277. 